\title{
Home School
}

National Cancer Institute

\section{Source}

National Cancer Institute. Home School. NCI Thesaurus. Code C159513.

Education that takes place outside of a traditional school, in a home or other facility, with the teaching being conducted by a parent, tutor, or online instructor. 